\title{
Medical disorders in people with recurrent depression
}

Anne Farmer, Ania Korszun, Michael J. Owen, Nick Craddock, Lisa Jones, Ian Jones, Jo Gray, Richard J. Williamson and Peter McGuffin

\section{Background}

Few studies have examined the rates of physical disorders in those with recurrent depression.

\section{Aims}

To examine self-reported physical disorders in people with recurrent depression compared with a psychiatrically healthy control group.

\section{Method}

As part of a genetic case-control association study, 1546 participants with recurrent depression and 884 controls were interviewed about lifetime ever treatment for 16 different physical health disorders.

\section{Results}

The cases group had a significantly higher frequency of
14 physical disorders and more obesity than the control group. After controlling for age, gender, body mass index (BMI) and multiple testing, those in the cases group had significantly higher rates of gastric ulcer, rhinitis/hay fever osteoarthritis, thyroid disease, hypertension and asthma.

\section{Conclusions}

People with recurrent depression show high rates of many common physical disorders. Although this can be partly explained by BMI, shared aetiological pathways such as dysfunction of the hypothalamic-pituitary axis may have a role.

\section{Declaration of interest}

None. Funding detailed in Acknowledgements.
Many studies have examined the prevalence of depression in people with a range of medical disorders. ${ }^{1}$ Moreover, general population-based epidemiological studies have noted high rates of comorbidity between physical illness and symptoms of depression and anxiety. ${ }^{2}$ However, few studies have examined the rates of physical disorders in those with well-defined recurrent depression, and none to our knowledge has compared such individuals with age-matched, psychiatrically healthy control participants. In this large case-control study we compared participants with recurrent depression with those selected for a range of medical disorders using an interview assessment method. Since many medical disorders are related to obesity, we also examined body mass index (BMI) in study participants and have controlled for BMI, gender and age when reporting effect size differences.

\section{Method}

\section{Study population}

All participants were interviewed by trained graduate psychologists about the lifetime occurrence of various physical health diagnoses as part of a genetic case-control association study of recurrent depression, the Depression Case-Control (DeCC) study. ${ }^{3}$ Participants who had experienced two or more episodes of major depression of at least moderate severity were recruited from psychiatric clinics and hospitals (26\%) and general practices $(46 \%)$, and through self-help groups and media advertisement (28\%) from three sites in the UK (Birmingham, Cardiff and London) during the years 2001-2004. Potential participants with depression were included if they were aged 18 years or over and of White European origin, and excluded if they had injecting drug dependence, depression occurring only in relation to substance misuse or a medical illness, or a personal/family history of mania or schizophrenia.

Control participants were recruited through the UK general practice-based Genetic-Environmental Nature of Emotional States in Siblings (GENESiS) study, ${ }^{4}$ and all were screened by telephone interview. Individuals were included in the control group if they had no past or present psychiatric disorder, were aged 18 years or over and were of White European origin. All participants gave written informed consent and the protocol was approved by the local ethics committees of the three participating institutions.

\section{Diagnostic instruments}

All participants with depression were given a face-to-face semistructured diagnostic interview, the Schedules for the Clinical Assessment of Neuropsychiatry (SCAN) version $2.1,{ }^{5}$ by trained interviewers to establish the diagnosis of recurrent depression according to either DSM-IV-TR or ICD-10. ${ }^{6,7}$ Items of psychopathology were rated for severity and duration for the peak-intensity $4-6$ weeks of symptoms (i.e. symptoms were at their worst) occurring during their worst and second-worst episodes of depression. The computerised version of the SCAN 2.1 is built on the iSHELL system, which is a computer-aided personal interviewing tool produced by the World Health Organization, ${ }^{8}$ and which provides DSM-IV and ICD-10 operationally defined diagnoses. Potential control group participants were interviewed by telephone using a modified version of the Past History Schedule, ${ }^{9}$ and were included if there was no evidence of past or present clinically significant psychiatric disorder. All participants also completed the Beck Depression Inventory ${ }^{10}$ to measure their mood at the time of interview.

For the lifetime diagnosis of physical health disorders, a short structured interview was given in which all participants in the cases and control groups were asked whether they had ever been treated by their general practitioner for the following health problems: asthma, diabetes (insulin-dependent and non-insulindependent), epilepsy, gastric ulcer, hypercholesterolaemia (elevated blood lipids), hypertension, kidney disease, liver disease, myocardial infarction, osteoarthritis, osteoporosis, rheumatoid arthritis, rhinitis or hay fever, stroke or thyroid disease. Their 
replies were scored as 'yes', 'no' or 'uncertain'. For the purpose of the analyses reported here, ratings scored as 'uncertain' were recoded conservatively as 'no'. The interview was given face to face for the cases group and by telephone interview for the control group.

In order to check the accuracy of self-report, the general practitioners of 30 representative participants (cases and controls) from this study, combined with 47 euthymic participants from a genetic case-control study of bipolar affective disorder who had also been interviewed about their physical health, were asked to complete a checklist regarding the medical disorders listed above and asked to indicate whether their patient had ever been treated for any of these disorders. Kappa statistics for self-report compared with general practitioner report for six of the more common disorders were calculated.

\section{Body mass index}

For the cases group, self-reported height and weight were recorded in the SCAN interview. Control participants were asked their current height and weight in the telephone interview. These data were used to calculate the BMI for each participant.

\section{Data analysis}

All phenotypic information from interviews and questionnaires was coded by assigning a number to each participant and removing any personal identifying information. This was first entered on an Excel spreadsheet, after which a data file was created using the Statistical Procedures for the Social Sciences (SPSS) version 11 for Windows for the statistical analyses. Group comparisons of the lifetime prevalence of the different physical health disorders were performed using simple contingency table analyses and binary logistic regression. In the logistic regression analyses, significance was assessed using the Wald statistic which is asymptotically distributed as a chi-square. Since several medical disorders are related to obesity, the participants were assigned to three BMI categories: normal (BMI under $25 \mathrm{~kg} / \mathrm{m}^{2}$ ), overweight (BMI $25 \mathrm{~kg} / \mathrm{m}^{2}$ or over but less than $30 \mathrm{~kg} / \mathrm{m}^{2}$ ) and obese (BMI $30 \mathrm{~kg} / \mathrm{m}^{2}$ or more). These categories were entered into the logistic analyses as a co-factor. As there was a significantly greater proportion of women in the cases group than in the control group, gender was also entered in the logistic analyses as a co-factor Similarly, since physical disorders occur more frequently with increasing age, all participants were scored according to whether they were at or above (scored as 1) or below (scored as 0 ) the median age.

\section{Results}

A total of 2430 participants completed the medical history interview (872 men and 1558 women), of whom 1546 (484 men and 1062 women) had a lifetime ever diagnosis of recurrent depression and 884 (388 men and 496 women) were psychiatrically healthy. All participants in the cases group fulfilled ICD-10 operational criteria for recurrent depression (i.e. SCAN-coding algorithm rating as moderately severe or severe for both the worst and the second-worst depressive episodes). All but 55 (4\%) cases also fulfilled DSM-IV criteria for major depression for both episodes. In 44 cases only one episode fulfilled DSM-IV criteria and in 11 cases neither episode fulfilled DSM-IV criteria.

Sixty-nine per cent of the cases group were women compared with $56 \%$ of the control group $\left(\chi^{2}=38.72\right.$, d.f. $\left.=1, P<0.001\right)$. In view of this significant difference, gender was controlled for in all comparisons of medical disorders. The mean age at interview of the cases group was 47.37 years $($ s.e.m. $=0.31$ ) and for the control group it was 47.71 (s.e.m. $=0.32$; Student's $t=0.77$, d.f. $=2142.51)$. The median age of the sample was 49.00 years.

\section{Participant differences between sites}

Participants from Birmingham were slightly older at interview (mean 49.33 years, s.d.=12.21) than those from Cardiff (mean 47.10 years, s.d. $=13.64$ ) and London (mean 45.82 years, s.d. $=10.60)$. In the cases group, those from London were younger (mean 21.27 years, s.d.=11.74) than those from Birmingham (mean 25.08 years, s.d.=11.99) and Cardiff (mean 23.82 years, s.d. $=10.91)$ at the start of their depressive illness, and Cardiff recruited a higher percentage of female participants $(74 \%)$ compared with London (67\%) and Birmingham (65\%).

\section{Body mass index}

Forty-two per cent of the cases group and $58 \%$ of the control group were of normal weight, whereas $34 \%$ of the cases and $32 \%$ controls were overweight, and $24 \%$ cases and $10 \%$ controls had a body weight within the obese range. Men in the cases group had significantly higher BMI values compared with men in the control group: cases group mean $=27.07 \mathrm{~kg} / \mathrm{m}^{2}$, s.d. $=4.78$, range 14.36-50.18; control group mean $=26.02 \mathrm{~kg} / \mathrm{m}^{2}$, s.d. $=4.55$, range 14.94-62.70 $(t=-2.76$, d.f. $=512.47, P=0.006)$. Similarly, women in the cases group had significantly higher BMI values than women in the control group: cases group mean $=26.85 \mathrm{~kg} / \mathrm{m}^{2}$, s.d. $=6.04$, range 16.02-53.15; control group mean $=24.51 \mathrm{~kg} / \mathrm{m}^{2}$, s.d. $=4.66$, range $16.56-51.79(t=-7.01$, d.f. $=746.85, P<0.001)$.

\section{Self-reported medical disorders}

\section{Comparison with general practitioner report}

Sixty-one of the 77 general practitioners (79\%) completed questionnaires regarding the medical histories of their patients. A further 5 general practitioners returned the forms uncompleted, commenting that the participant was no longer registered with the practice. Eleven general practitioners failed to respond.

The majority of disorders were reported infrequently by both participants and general practitioners. In addition, patients with bipolar disorder from the genetic study sample were not asked about gastric ulcer or thyroid disease, and none of the general practitioners reported hay fever among these participants; hence these disorders were not included in the reliability analyses. The kappa coefficients for the following medical disorders in participants were as follows: asthma $\kappa=0.73$ (s.e.m. $=0.11$ ), diabetes $\kappa=0.91$ (s.e.m. $=0.06$ ), hypertension $\kappa=0.87$ (s.e.m. $=0.06$ ), hypercholesterolaemia $\kappa=0.65$ (s.e.m. $=0.10$ ), myocardial infarction/ angina $\kappa=0.82$ (s.e.m. $=0.13$ ) and arthritis $\kappa=0.74$ (s.e.m. $=0.14$ ). Percentage agreement between general practitioners and participants for the presence or absence of a medical disorder was 93\%. The mean kappa coefficient for the six disorders in the participants participating in the two studies was 0.79 and the mean s.e.m. was $0.10(P<0.001)$.

\section{Cases V. controls}

Lifetime prevalence rates for common medical disorders in the cases and control groups are shown in Table 1. Hypertension, asthma and osteoarthritis had the highest lifetime prevalences in the cases group $(16.49 \%, 16.48 \%$ and $10.67 \%$ respectively) and asthma, hypertension and hypercholesterolaemia the highest lifetime prevalences in the control group $(9.39 \%, 7.13 \%$ and $6.10 \%$ respectively). Five disorders had low prevalence in both cases and controls, namely insulin-dependent diabetes, epilepsy, kidney 


\begin{tabular}{|c|c|c|c|c|}
\hline \multirow[b]{2}{*}{ Medical disorder } & \multicolumn{2}{|c|}{ Lifetime prevalence, \% } & \multirow[b]{2}{*}{$\chi^{2}($ d.f. $=1)$} & \multirow[b]{2}{*}{$P^{a}$} \\
\hline & Cases group ( $n=1547$ ) & Control group ( $n=884$ ) & & \\
\hline Asthma & 16.48 & 9.39 & 23.65 & $<0.001$ \\
\hline \multicolumn{5}{|l|}{ Diabetes } \\
\hline Insulin-dependent & 1.10 & 1.25 & 0.11 & NS \\
\hline Non-insulin-dependent & 2.78 & 1.36 & 5.12 & 0.02 \\
\hline Epilepsy & 1.81 & 0.34 & & $0.001^{b}$ \\
\hline Gastric ulcer & 4.98 & 1.24 & 22.47 & $<0.001$ \\
\hline Hypercholesterolaemia & 9.24 & 6.10 & 7.47 & 0.006 \\
\hline Hypertension & 16.49 & 7.13 & 43.39 & $<0.001$ \\
\hline Kidney disease & 1.36 & 1.13 & 0.23 & NS \\
\hline Liver disease & 2.07 & 0.90 & 4.71 & 0.03 \\
\hline Myocardial infarction & 3.71 & 1.59 & 8.81 & 0.003 \\
\hline Osteoarthritis & 10.67 & 3.95 & 33.64 & $<0.001$ \\
\hline Osteoporosis & 3.04 & 1.24 & 7.79 & 0.005 \\
\hline Rheumatoid arthritis & 4.40 & 2.25 & 7.38 & 0.007 \\
\hline Rhinitis/hay fever & 7.05 & 3.16 & 15.96 & $<0.001$ \\
\hline Stroke & 1.75 & 0.45 & & $0.005^{\mathrm{b}}$ \\
\hline Thyroid disease & 8.00 & 2.38 & 31.66 & $<0.001$ \\
\hline $\begin{array}{l}\text { NS, not significant. } \\
\text { a. Two-sided. } \\
\text { b. Fisher's exact test. }\end{array}$ & & & & \\
\hline
\end{tabular}

disease, liver disease and stroke. With the exception of insulindependent diabetes and kidney disease, all other disorders were reported significantly more frequently in cases than controls.

Table 2 shows the odds ratios, $95 \%$ confidence intervals, Wald statistic and significance for the binary logistic regression for cases compared with controls for each medical disorder from Table 1, for which there was a significant difference on the simple contingency tests (14 disorders). Presence or absence of the disorder was the outcome variable, and affected status (case or control), BMI (normal, overweight or obese), gender and age (at/above or below the median) were co-factors. A Bonferroni correction for multiple testing was applied. The table shows that the odds ratios for comorbid medical disorders and depression that remained significant following the Bonferroni correction after controlling for BMI, gender and age, were for gastric ulcer, rhinitis/hay fever, osteoarthritis, thyroid disease, hypertension and asthma (odds ratios $4.31,3.29,3.05,2.78,2.20$ and 2.19 respectively).

\section{Discussion}

\section{Case-control differences for reported medical disorders}

Fourteen physical disorders were significantly more frequent in participants with recurrent depression than in psychiatrically healthy controls. However, when BMI, age and gender were controlled for, depression remained a predictive factor for only six disorders: gastric ulcer, asthma, rhinitis, hypertension, thyroid disease and osteoarthritis. For the remaining physical health problems, the difference between those with and without each disorder could be accounted for by BMI, age or gender, or were

\begin{tabular}{|c|c|c|c|c|}
\hline Medical disorder & $\begin{array}{l}\text { Cases } v \text {. controls } \\
\text { OR }(95 \% \mathrm{Cl})\end{array}$ & Wald statistic & $P$ & $\begin{array}{l}P \text { corrected for } \\
\text { multiple testing }\end{array}$ \\
\hline Asthma & 2.19 (1.53-3.13) & 18.57 & 0.000016 & 0.00022 \\
\hline Diabetes (non-insulin-dependent) & $2.06(0.84-5.04)$ & 2.47 & NS & \\
\hline Epilepsy & $3.06(0.90-10.47)$ & 3.19 & NS & \\
\hline Gastric ulcer & $4.31(1.94-9.57)$ & 12.83 & 0.00034 & 0.0047 \\
\hline Hypercholesterolaemia & $1.64(1.06-2.56)$ & 4.86 & 0.028 & 0.39 \\
\hline Hypertension & $2.20(1.51-3.22$ & 16.70 & 0.000044 & 0.00062 \\
\hline Liver disease & 2.69 (1.01-7.13) & 3.94 & 0.047 & 0.66 \\
\hline Myocardial infarction & $2.70(1.24-5.87$ & 6.25 & 0.012 & 0.17 \\
\hline Osteoarthritis & $3.05(1.83-5.08)$ & 18.17 & 0.00003 & 0.00042 \\
\hline Osteoporosis & $3.35(1.38-8.13)$ & 7.11 & 0.008 & 0.11 \\
\hline Rheumatoid arthritis & $2.72(1.31-5.63)$ & 7.24 & 0.007 & 0.10 \\
\hline Rhinitis/hay fever & $3.29(1.77-6.13)$ & 14.05 & 0.00018 & 0.0025 \\
\hline Stroke & $3.33(0.97-11.50)$ & 3.63 & NS & \\
\hline Thyroid disease & $2.78(1.55-5.01)$ & 11.63 & 0.00065 & 0.0091 \\
\hline
\end{tabular}


found to be non-significant following correction for multiple testing.

\section{Body mass index}

Both men and women in the cases group had significantly higher BMIs compared with men and women in the control group. Although the percentages of the two groups were similar in the overweight range (BMI $25-29 \mathrm{~kg} / \mathrm{m}^{2}$ ), a greater proportion of the cases group were in the obese range (BMI $30 \mathrm{~kg} / \mathrm{m}^{2}$ and over) and substantially fewer were in the normal range (BMI $<25 \mathrm{~kg} / \mathrm{m}^{2}$ ) compared with controls. Thus, around a quarter of the men and women with depression were categorised as obese, which increases their susceptibility to the attendant physical health problems. In this study obesity was associated with an increase in self-reported rates of hypercholesterolaemia, type II diabetes and myocardial infarction. High rates of obesity may be caused by the weight-gaining properties of some antidepressant medication, or because people who are depressed take less exercise and/or 'comfort' eat. However, it is also possible that factors such as a shared common heritable pathogenesis may be operating. ${ }^{11}$ Whatever the mechanism, this and other studies ${ }^{11,12}$ suggest that clinicians need to pay more attention to the weight of their patients with recurrent depression.

\section{Comparison with other studies of physical disorders and depression}

There have been many more studies examining rates of depression in those with specific physical disorders than those investigating the physical health of those with major depression. Noteworthy in relation to our findings is the study by Taylor et al, who observed that ulcers occurred ten times more frequently in elderly participants with depression compared with controls without depression, ${ }^{13}$ and a recent literature review suggested that depressive symptoms are more common in people with asthma than in members of the general population. ${ }^{14}$ It has also been shown that individuals with any history of allergy (including rhinitis/hay fever) are significantly more likely to be diagnosed with major depression. ${ }^{15}$ The link between thyroid dysfunction and depression has been well-established, and a recent large, registerbased study in Denmark showed that patients hospitalised with hypothyroidism had a greater risk of a subsequent admission with depression or bipolar disorder than controls. ${ }^{16}$ Previous studies have shown elevated blood pressure associated with depression, ${ }^{17}$ as we have found in our study, and prospective studies have also suggested that depression may be a risk factor for the development of hypertension. ${ }^{18}$ The association between depression and chronic painful conditions such as osteoarthritis is also wellrecognised, ${ }^{19}$ with studies showing that treatment of depression also reduces somatic symptoms.

One large epidemiological study undertaken by the New Mexico Department of Health and Centers for Disease Control and Prevention in the USA examined the association between physical disorder and the 1-month prevalence of depression in over 5000 participants from the general population. ${ }^{20}$ In this study, $30 \%$ of participants with depression were obese (BMI $30 \mathrm{~kg} / \mathrm{m}^{2}$ and above), i.e. 5-6\% more than were found in the study reported here. Compared with individuals without depression, participants with depression were significantly more likely to report treatment for hypertension, asthma and arthritis. However, the New Mexico study did not control for possible confounding factors.

In another large epidemiological study of physical illness and depression, the Canadian Community Health Survey, ${ }^{1} 115071$ participants were screened by self-report questionnaire for physical diagnoses and a brief medical interview was used to diagnose depression in the previous year. As this Canadian survey was one of the largest studies reporting depression in range of physical disorders, it is reasonable to compare their results with ours despite methodological differences. Although they controlled only for age and gender and not for BMI in their logistic regression analyses, none the less these authors found significant odds ratios for co-occurring depression of 2.8 for ulcers, 1.9 for both asthma and arthritis, 1.4 for thyroid disease and 1.2 for hypertension, which are comparable to our findings for these disorders.

Evidence from our own and the above-mentioned studies lends some support for the hypothesis that there are shared aetiological factors between recurrent depression, obesity and the six physical disorders. One possible mechanism includes a role for stress and activation of the hypothalamic-pituitary-adrenal (HPA) axis. ${ }^{21}$ Elevated cortisol level is a frequent finding in depression, and it has been proposed that this may be caused by both acute and/or protracted exposure to stress. ${ }^{22}$ Hypercortisolaemia in Cushing's syndrome is associated with gastric ulcers and obesity. Activation of the HPA axis has been shown to exert hyperphagic and antithermogenic effects, ${ }^{23}$ and visceral obesity may be associated with increased cortisol clearance. Hence, abnormal cortisol regulation may link both obesity and gastric ulcers with depression. Proinflammatory cytokines are produced in excess in people with asthma, rhinitis and possibly also osteoarthritis, ${ }^{24}$ and these cytokines are also associated with inflammatory activation of the HPA axis. ${ }^{15}$ Similarly, Nyklicek et al have shown that people with hypertension had an enhanced HPA axis and immune system reactivity to stress. ${ }^{25}$ Hence HPA axis activation from inflammatory processes could link depression with asthma, hay fever, osteoarthritis and hypertension. Various studies have shown abnormalities of the hypothalamicpituitary-thyroid axis in depression, ${ }^{26}$ which suggests that central hypothalamic-pituitary dysfunction may be associated with thyroid abnormalities in addition to dysfunction in the glucocorticoid system.

Clearly, all of the above is speculative and requires confirmation from further studies. The limitations of our study also need to be considered; for example, the large sample size imposed some methodological constraints. Although we carefully defined participants and controls in terms of the presence or absence of recurrent depression by undertaking a detailed semi-structured interview, we relied on self-report with regard to physical health problems as well as height and weight to calculate BMI. We hoped that asking directly about treatment received for the physical disorders would have ensured that some form of medical intervention had occurred and that the diagnosis would have been made by a doctor. This would seem to be the case, since in a sample of 61 people with affective disorders and controls, the presence or absence of physical disorder was confirmed by their general practitioner $93 \%$ of the time. In addition, the kappa coefficients for individual disorders ranged from 0.65 to 0.91 , indicating 'substantial' to 'almost perfect' agreement. ${ }^{27}$ Thus, we are confident that self-report gives a reasonably accurate account of comorbid medical disorders in these participants. Second, despite our having recruited over 2000 individuals and having found significant differences between cases and controls for a number of physical health disorders, the frequencies of several disorders were low, limiting the power to detect significant odds ratios in the less common disorders. Also, the average age of participants was the mid-forties, so the majority of them had not reached the period of risk for many of the physical illnesses. Third, it is also possible that retrospective rating by participants with recurrent depression of their physical health could have been 
influenced by their present mood. Indeed, we did find a small but significant correlation between scores on a self-report measure of present mood, the Beck Depression Inventory, ${ }^{10}$ and number of medical disorders reported in both cases and controls. However, Beck Depression Inventory score contributed only $1.5 \%$ of the variance in number of physical disorders reported in cases and $1 \%$ in controls. Last, we used BMI as a measure of obesity, and there is now evidence that it is abdominal or visceral fat deposition that is most harmful to health. ${ }^{11}$ Consequently, waist measurement or waist/hip ratio would have been a more accurate measure of the risk of obesity to physical health.

Although long neglected, the physical health of those with schizophrenia is beginning to be addressed, particularly in relation to the weight gain associated with antipsychotic drugs. Our study suggests that attention also needs to be paid to the physical health needs of people with depression.

Anne Farmer, MD, FRCPsych, Medical Research Council, Social Genetic and Developmental Psychiatry Centre, Institute of Psychiatry, London; Ania Korszun, $\mathrm{PhD}$, MRCPsych, Department of Psychiatry, St Bartholomew's and Royal London Medical School, London; Michael J. Owen, PhD, FRCPsych, Nick Craddock, PhD FRCPsych, MRCPsych, Department of Psychological Medicine, Wales School of Medicine, Cardiff University, Cardiff; Lisa Jones, PhD, Department of Psychiatry, University of Birmingham, Queen Elizabeth Psychiatric Hospital, Birmingham; lan University of Biningham, Queen Eliza e J Psychiatric Hospital, Birmingham; lan Jones, PhD, MRCPSch, Department of Psychological Medicine, Wales School of Medicine, Cardiff University, Cardiff; Jo Gray, BSc, Richard J. Williamson, PhD, Peter McGuffin, PhD, FRCP, FRCPsych, Medical Research Council, Social Genetic and Developmental Psychiatry Centre, Institute of Psychiatry, London, UK

Correspondence: Dr Anne Farmer, Medical Research Council, Social Genetic and Developmental Psychiatry Centre, Institute of Psychiatry, De Crespigny Park, London SE5 8AF, UK. Email: a.farmer@iop.kcl.ac.uk

First received 28 Mar 2007, final revision 21 Nov 2007, accepted 13 Dec 2007

\section{Acknowledgements}

The study was funded by a project grant from the Medical Research Council.

\section{References}

1 Patten SB, Beck CA, Kassan A, Williams JV, Barbui C, Metz LM. Long-term medical conditions and major depression: strength of association for specific conditions in the general population. Can J Psychiatry 2005; 50: 195-202.

2 Paykel ES, Brugha T, Fryer T. Size and burden of depressive disorders in Europe. Eur Neuropsychopharmacol 2005; 15: 411-23.

3 Korszun A, Moskvina V, Brewster S, Craddock N, Ferrero F, Gill M, Jones IR Jones LA, Maier W, Mors O, Owen MJ, Preisig M, Reich T, Rietschel M, Farmer A. Familiarity of symptom dimensions in depression. Arch Gen Psychiatry 2004; 61: 468-74.

4 Rijsdijk FV, Sham PC, Sterne A, Purcell S, McGuffin P, Farmer A, Goldberg D, Mann A, Cherny SS, Webster M, Ball D, Eley TC, Plomin R. Life events and depression in a community sample of siblings. Psychol Med 2001; 31 : 401-10.

5 Wing JK, Babor T, Brugha T, Burke J, Cooper JE, Giel R, Jablenski A, Regier D, Sartorius N. SCAN: Schedules for Clinical Assessment in Neuropsychiatry. Arch Gen Psychiatry 1990; 47: 589-93.
6 American Psychiatric Association. Diagnostic and Statistical Manual of Mental Disorders (4th edn, text revision) (DSM-IV-TR). APA, 2000.

7 World Health Organization. The ICD-10 International Classification of Diseases, Chapter F: Mental and Behavioural Disorders. Diagnostic Criteria for Research. WHO, 1993.

8 Celik C. Computer Assisted Personal Interviewing Application for the Schedules for the Clinical Assessment in Neuropsychiatry Version 2.1 and Diagnostic Algorithms for WHO ICD10 chapter V DCR and for Statistical Manual IV. Release 1 Ed. 1.0.3.5 Win9xNT. World Health Organization, 2003.

9 McGuffin P, Katz R, Aldrich J. Past and Present State Examination: the assessment of lifetime ever psychopathology. Psychol Med 1986; 16: 461-5.

10 Beck AT. The Beck Depression Inventory. Psychological Corporation, 1978.

11 McElroy SL, Kotwal R, Malhotra S, Nelson EB, Keck PE, Nemeroff CB. Are mood disorders and obesity related? A review for the mental health professional. J Clin Psychiatry 2004; 65: 634-51.

12 Faith MS, Matz PE, Jorge MA. Obesity-depression associations in the population. J Psychosom Res 2002; 53: 935-42.

13 Taylor WD, McQuoid DR, Krishnan KRR. Medical comorbidity in late-life depression. Int J Geriatr Psychiatry 2004; 19: 935-43.

14 Zielinski TA, Brown ES, Nejtek VA, Khan DA, Moore JJ, Rush AJ. Depression in asthma: prevalence and clinical implications Prim Care Companion J Clin Psychiatry 2004; 2: 153-8.

15 Hurwitz EL, Morgenstern H. Cross-sectional associations of asthma, hay fever and other allergies with major depression and low back pain among adults aged 20-39. Am J Epidemiol 1999; 150: 1107-16.

16 Thomsen AF, Kvist TK, Andersen PK, Kessing LV. Increased risk of developing affective disorder in patients with hypothyroidism: a register based study. Thyroid 2005; 15: 700-7.

17 Scalco AZ, Scalco MZ, Azul JB, Lotufo Neto F. Hypertension and depression. Clinics 2005; 60: 241-50.

18 Jonas BS, Franks P, Ingram DD. Are symptoms of anxiety and depression risk factors for hypertension? Longitudinal evidence from the National Health and Nutrition Examination Survey I Epidemiologic Follow-up Study. Arch Family Med 1997; 6: 43-9.

19 Katon W, Lin EH, Kroenke K. The association of depression and anxiety with medical symptom burden in patients with chronic medical illness. Gen Hosp Psychiatry 2007; 29: 147-55.

20 Centers for Disease Control and Prevention. Mental health in the United States: health risk behavior and conditions among persons with depression New Mexico 2003. MMWR Morb Mortal Wkly Rep 2005; 7: 989-91.

21 Sherwood E, Varghese FP, McEwen BS. Association of depression with medical illness: does cortisol play a role? Biol Psychiatry 2004; 55: 1-9.

22 Seckl JR, Meaney MJ. Glucocorticoid programming. Ann N Y Acad Sci 2004; 1032: $63-84$

23 Drapeau V, Therrien F, Richard D, Tremblay A. Is visceral obesity a physiological adaptation to stress? Panminerva Med 2003; 45: 189-95.

24 Amin AR, Di Cesare PE, Vyas $P$, Attur M, Tzeng E, Billiar TR, Stuchin SA, Abramson $\mathrm{SB}$. The expression and regulation of nitric oxide synthase in human osteoarthritis-affected chondrocytes: evidence for up-regulated neuronal nitric oxide synthase. J Exp Med 1995; 182: 2097-102.

25 Nyklicek I, Bosch JA, Amerongen AV. A generalised physiological hyperreactivity to acute stressors in hypertensives. Biol Psychol 2005; 70 : 44-51.

26 Sullivan PF, Wilson DA, Mulder RT, Joyce PR. The hypothalamic-pituitarythyroid axis in major depression Acta Psychiatr Scand 1997; 95: 370-8.

27 Landis RJ, Koch GG. The measurement of observer agreement for categorical data. Biometrics 1977; 33: 159-74. 